\title{
NEUROPROTECTIVE EFFECTS OF AQUEOUS EXTRACT OF HYDROCOTYLE JAVANICA IN AMELIORATING NEUROBEHAVIORAL ALTERATION INDUCED BY MERCURY
}

\author{
PANKAJ PHUKAN ${ }^{1}$, SANJIT NAMASUDRA ${ }^{1}$, MEENAKSHI BAWARI ${ }^{1 *}$, MAHUYA SENGUPTA $^{2}$ \\ ${ }^{1}$ Department of Life Science and Bioinformatics, Assam University, Assam, India. ${ }^{2}$ Department of Biotechnology, Assam University, Assam, \\ India. Email: mbawari.aus@gmail.com
}

Received: 10 October 2018, Revised and Accepted: 22 November 2018

\section{ABSTRACT}

Objective: This study aims to assess the effects of the aqueous extract of Hydrocotyle javanica (HJ) in ameliorating mercury-induced neurobehavioral toxicity.

Methods: For the study, 36 adult male Swiss albino mice of 25-30 g in weight were taken. They were equally divided into six groups. Group I was treated with distilled water, Group II was treated with mercuric chloride (1.5 mg/kg), Group III was treated with HJ extract low dose (100 mg/kg), Group IV was treated with HJ extract high dose $(200 \mathrm{mg} / \mathrm{kg})$, Group V was treated with mercuric chloride plus HJ extract low dose, and Group VI was treated with mercuric chloride plus TB extract high dose. In all the groups, the doses were administered orally through oral gavage tube and the treatment lasted for 14 days. The behavioral effects evaluated were locomotor activity in the open field test, immobility in forced swimming test and anxiety in elevated plus maze test, spatial learning ability and memory in the Morris water maze test.

Results: The present study showed that mercury exposure significantly decreased the locomotor activity ( $<<0.001$ ), number of annulus crossovers $(\mathrm{p}<0.001)$, number of open arm entries $(\mathrm{p}<0.01)$, time spent in open arms $(\mathrm{p}<0.001)$, and increased escape latency ( $<<0.01)$, path length $(\mathrm{p}<0.001)$, and immobility $(\mathrm{p}<0.001)$ in mice. The aqueous extract of $\mathrm{HJ}$ significantly alleviated the neurotoxic effects of mercury. The aqueous extract of HJ showed to increase the locomotor activity $(\mathrm{p}<0.01)$, number of annulus crossovers $(\mathrm{p}<0.001)$, number of open arm entries ( $<<0.05)$, and time spent in open arms $(\mathrm{p}<0.05)$, which was decreased in mercury-exposed mice. The HJ extract also showed to decrease the immobility ( $<<0.001)$, escape latency $(\mathrm{p}<0.05)$, and path length $(\mathrm{p}<0.001)$ in mercury-exposed mice.

Conclusion: The result of the study shows that neurobehavioral changes induced by mercuric chloride were significantly reversed by the aqueous extract of HJ. Thus, base on the present study, it is concluded that $\mathrm{HJ}$ is effective in ameliorating the neurobehavioral deficits induced by mercury.

Keywords: Medicinal plant, Neuroprotection, Neurotoxicity, Behavior, Heavy metal.

(C) 2019 The Authors. Published by Innovare Academic Sciences Pvt Ltd. This is an open access article under the CC BY license (http://creativecommons. org/licenses/by/4. 0/) DOI: http://dx.doi.org/10.22159/ajpcr.2019.v12i1.30230

\section{INTRODUCTION}

Medicinal plants have been playing an important role since ancient times in treating various kinds of diseases [1]. Due to the side effects of chemical drugs, herbal remedies are gaining popularity [2]. Herbs can be used as an alternative remedy for the treatment of different neurological disorders. Several scientific studies reveal that herbal extracts and active constituents isolated from different herbs can ameliorate nerve disorders, improve learning and memory [3-4]. Many studies show that high exposure to mercury induces changes in the central nervous system (CNS), potentially leading to irritability, fatigue, behavioral changes, tremors, headaches, hearing and cognitive loss, dysarthria, incoordination, hallucinations, and death [5-7]. Although mercury-induced neurotoxicity is an extensively reported phenomenon, the molecular mechanisms underlying its toxicity are not fully understood. Notwithstanding the massive efforts in the search for new drugs that counteract mercurial toxicity, there are no effective treatments available which completely abolish its toxic effects. Taking into account the absence of effective treatments for mercury poisoning and medicinal properties of Hydrocotyle javanica (HJ), this study aims to study the effects of $\mathrm{HJ}$ in alleviating mercury-induced neurotoxicity. This is also the first study to evaluate the neuroprotective effects of $\mathrm{HJ}$.

\section{MATERIALS AND METHODS}

\section{Plants materials}

The plant material HJ was collected from Dibrugarh district of Assam, India and was identified and authenticated by Botanical Survey of India, Shillong as HJ Thunb (No.: BSI/ERC/Tech/2017).

\section{Animals}

The Swiss albino mice weighing between $20 \mathrm{~g}$ and $30 \mathrm{~g}$ were used in this study. The mice were obtained from the Pasture Institute, Shillong. All the mice were then housed in cages under standard environmental conditions and had free access to food and water ad libitum. The experiments were performed in accordance with the guidelines in the care and use of laboratory animals and were approved by the Ethical Committee of the Assam University, Silchar (IEC/AUS/C/2014-010dt-14/08/14).

\section{Mercury}

Mercuric chloride is obtained from HiMedia.

\section{Preparation of extract}

The plant materials, HJ was shade dried under room temperature for about 45 days. The shade-dried plants were powdered, and the extract was prepared using Soxhlet extractor, and after extraction, the sample was filtered with No. 1 Whatman filter paper, and then the filtrate was evaporated to dryness at $40^{\circ} \mathrm{C}$. The dried extract was weighed and dissolved in distilled water to give the required concentration before administration to the experimental animals.

\section{Preliminary phytochemical screening}

The extract was screened for the presence of various phytochemical constituents, namely alkaloids, carbohydrates, flavonoids, saponin, proteins, amino acid, oils, and fats [8-13].

\section{Dose selection}

The dosage of the extract was determined after toxicity test $\left(\mathrm{LD}_{50}\right)$ median lethal dose described by Lorke [14]. The $100 \mathrm{mg} / \mathrm{kg}$ b.wt and $200 \mathrm{mg} / \mathrm{kg}$ b.wt were taken as the low and high doses, respectively. 


\section{Experimental design}

All the animals were randomly divided into six groups, each containing six mice. The groups of mice were treated as follows: (i) Control (distilled water), (ii) mercuric chloride (1.5 mg/kg), (iii) plant extract low dose $(100 \mathrm{mg} / \mathrm{kg}$ ), (iv) plant extract high dose (200 mg/kg), (v) mercuric chloride+Plant extract low dose, and (vi) mercuric chloride+Plant extract high dose. All administrations were performed orally to the respective group up to a volume of $2 \mathrm{ml} / 100 \mathrm{~g}$ body weight for a period of 14 days. The experiments were performed $1 \mathrm{~h}$ after the administration of the last dose.

\section{Open field test}

The locomotor activity was assessed using the open-field apparatus after Pardon et al. with slight modifications. The apparatus, made of wood, had a floor of $50 \mathrm{~cm} \times 50 \mathrm{~cm}$ divided by black lines into 25 squares of $10 \mathrm{~cm} \times 10 \mathrm{~cm}$. The walls were of $25 \mathrm{~cm}$ in height. The test room was illuminated at the same intensity as the colony room. Each mouse was placed in the center of the open field, and its behavior was observed for $5 \mathrm{~min}$. The parameters evaluated were the total number of squares crossed. At the end of each test, the whole area was cleaned with a wet sponge and a dry paper towel. Doses were administered orally $60 \mathrm{~min}$ before the test session [15].

\section{Forced swimming test}

The forced swim test was used for the evaluation of antidepressant activity in mice. The forced swimming test was performed according to the procedure described by Porsolt with slight modifications. Briefly, the animals were individually forced to swim in a transparent glass vessel ( $25 \mathrm{~cm}$ high, $15 \mathrm{~cm}$ in diameter) filled with $(12.5 \mathrm{~cm}$ high) water at $23 \pm 1^{\circ} \mathrm{C}$. The duration of immobility (in second) was measured for $5 \mathrm{~min}$. After the test mice were removed from the glass vessel and then dried and placed in their home cage. "Immobility" was defined as floating and treading water just enough to keep the nose above water. The immobility reflected a state of lowered mood in which the animals had given up hope of finding an exit and had resigned themselves to the experimental situation. The water was changed after every other trial [16].

\section{Elevated plus maze test}

The elevated plus maze is an animal model where the behavioral repertoire of rodents is used to detect effects on anxiety. The test is based on the natural aversion of mice for open and elevated areas, as well as on their natural, spontaneous exploratory behavior in novel environments. Locally fabricated wooden elevated plus maze apparatus consisting of two open arms $(30 \mathrm{~cm} \times 8 \mathrm{~cm})$ and two enclosed arms $(30 \mathrm{~cm} \times 8 \mathrm{~cm} \times 15 \mathrm{~cm}$ ) having an open roof was used. The maze was elevated to the height of $40 \mathrm{~cm}$ from the floor in a dimly lit room. Mice were placed individually at the center of the elevated plus maze test facing an enclosed arm and allowed to explore the maze for $5 \mathrm{~min}$. The time spent by the mouse on the open and enclosed arm and the center and also the number of entries in open arms were recorded. Arm entries were defined as entry of all four paws into an arm. The apparatus was thoroughly cleaned after removal of the mice. Increased exploratory activity in the open arm was taken as an indication of anxiolytic activity [17].

\section{Morris water maze test}

The apparatus used for Morris water maze was a circular swimming pool of $110 \mathrm{~cm}$ diameter and $30 \mathrm{~cm}$ high, filled to a depth of $15 \mathrm{~cm}$ with water maintained at $23 \pm 1^{\circ} \mathrm{C}$. The water maze task was performed as described by Vorhees and Williams, 2006. Briefly, the mice were trained for 5 consecutive days, followed by the probe trial on day 6 . The mice were let down in four random places (North, South, East, and West) in the pool. The order of these was changed daily in a random manner. The mice were trained 4 times/day ( $60 \mathrm{~s} /$ trial). Animals not finding the platform within this time limit were either placed on the platform or guided to it. After the $60 \mathrm{~s}$ swim, they were allowed to stay on the platform for $15 \mathrm{~s}$ before the next swim trial. Single probe trials to test reference memory were conducted 1 day after the last training session.
Mice were released at a random start position and were allowed to swim for $30 \mathrm{~s}$ in the absence of the platform. In this test escape latency, i.e., the time taken to find the hidden platform, path length, i.e., the distance traveled by the mice to find the hidden platform and number of annulus crossovers were measured. The tracks were recorded using a video camera and animal tracker software [18]. The latencies and path length of training days 1-5 were compared with the average latency and path length for each day. For the analysis of the probe tests, the number of target annulus crossovers was compared [19].

\section{Statistical analysis}

SPSS was used for data analysis. Statistical significance of difference was calculated using one-way analysis of variance followed by Tukey's procedure for multiple comparisons. The data were expressed as mean \pm SEM. $\mathrm{p}<0.05$ was considered statistically significant.

\section{RESULTS}

\section{Preliminary phytochemical screening}

The results of phytochemical screening showed the presence of flavonoids, saponin, carbohydrates, and phenolic compounds (Table 1).

\section{Open field test}

The results of the open field test for locomotor activity during the 5 min duration is shown in Fig. $1 \mathrm{~A}$ significant decrease in the number of squares crossed was observed in Group II which was treated with mercuric chloride as compared to the Group I, i.e., controls ( $\mathrm{p}<0.001)$. However, a significant increase in the number of squares crossed was observed in Group I ( $p<0.001)$, Group III $(\mathrm{p}<0.001)$, Group IV $(\mathrm{p}<0.001)$, Group V $(\mathrm{p}<0.05)$, and Group VI $(\mathrm{p}<0.01)$ as compared to Group II.

\section{Forced swimming test}

The immobility in the forced swimming test is reported in Fig. 2. A significant increase in immobility was observed in Group II which was treated with mercuric chloride as compared to the Group I, i.e., controls $(\mathrm{p}<0.001)$. However, a significant decrease in the immobility time was observed in Group I ( $p<0.001)$, Group III $(p<0.001)$, Group IV ( $p<0.001)$, Group V ( $<<0.001)$, and Group VI $(\mathrm{p}<0.001)$ as compared to Group II.

\section{Elevated plus maze test}

The results obtained from the elevated plus maze test are reported in Figs. 3 and 4. A significant decrease in the time spent in the open arms $(p<0.001)$ and the number of entries into the open arms $(p<0.01)$ was observed in Group II as compared to Group I, i.e., control. However, a significant increase in the time spent in the open arms were observed in Group I $(\mathrm{p}<0.001)$, Group III $(\mathrm{p}<0.001)$, Group IV $(\mathrm{p}<0.001)$, Group V ( $<<0.05)$, and Group VI $(\mathrm{p}<0.05)$ as compared to Group II and a significant increase in the number of entries in the open arms was found in Group I ( $p<0.01)$, Group III ( $p<0.01$ ), Group IV ( $<<0.01)$, and Group VI $(p<0.05)$ as compared to Group II. However, though there was a slight decrease in open arm entries in the Group V as compared to Group II, it was not found to be statistically significant. The time spent in the closed arms was also observed to decrease in Group I $(\mathrm{p}<0.001)$, Group III $(\mathrm{p}<0.001)$, Group IV $(\mathrm{p}<0.001)$, Group V ( $\mathrm{p}<0.01)$,

Table 1: Phytochemical screening of aqueous extract of $\mathrm{HJ}$

\begin{tabular}{lll}
\hline Alkaloids & Mayer's test & -ve \\
& Wagner's test & $-\mathrm{ve}$ \\
Carbohydrates & Fehling's test & $+\mathrm{ve}$ \\
& Benedict's test & $+\mathrm{ve}$ \\
Phenolic Compounds & Ferric chloride test & $+\mathrm{ve}$ \\
& Alkaline reagent test & $+\mathrm{ve}$ \\
Saponin & Kokate 1999 & $+\mathrm{ve}$ \\
Proteins/Amino Acids & Biuret test & $-\mathrm{ve}$ \\
& Ninhydrin test & $-\mathrm{ve}$ \\
Oils/Fats & Spot test & $-\mathrm{ve}$ \\
& Saponification test & $-\mathrm{ve}$ \\
\hline
\end{tabular}

HJ: Hydrocotyle javanica, -ve: Absent, +ve: Present 


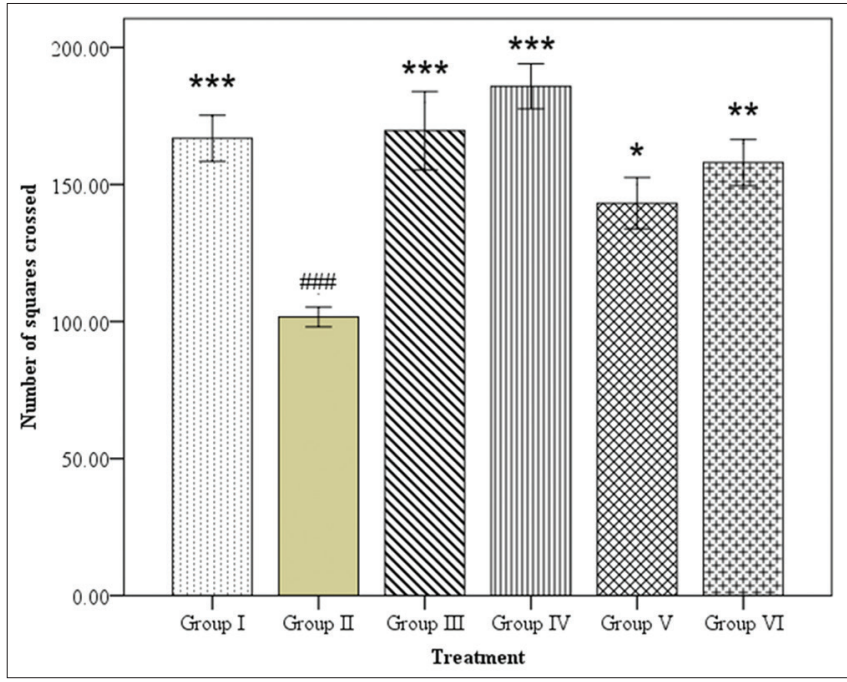

Fig. 1: Locomotor activity in an open field test. Each column represents mean $\pm \operatorname{SEM}(n=6)$. Comparisons were made using one-way analysis of variance followed by Turkey's multiple comparison test $\left({ }^{*} \mathrm{p}<0.05 ;{ }^{* *} \mathrm{p}<0.01 ;{ }^{* * *} \mathrm{p}<0.001\right.$ vs. Group II and ${ }^{\#} \mathbf{p}<0.05 ; "{ }^{\# \#} \mathbf{p}<0.01 ;{ }^{\# \# \#} \mathbf{p}<0.001$ vs. Group I)

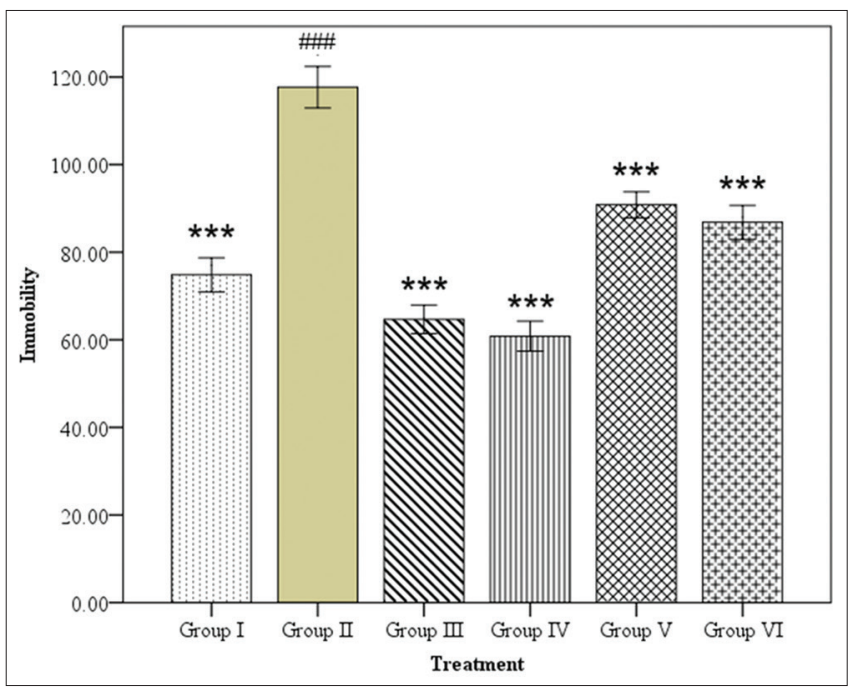

Fig. 2: Immobility in forced swimming test. Each column represents mean $\pm \operatorname{SEM}(n=6)$. Comparisons were made using one-way analysis of variance followed by Turkey's multiple comparison test $\left({ }^{*} \mathbf{p}<0.05 ;{ }^{* *} \mathbf{p}<0.01 ;{ }^{* * *} \mathbf{p}<0.001\right.$ vs. Group II and ${ }^{\#} \mathbf{p}<0.05 ;{ }^{\# \#} \mathbf{p}<0.01 ;{ }^{\# \# \#} \mathbf{p}<0.001$ vs. Group I)

and Group VI $(\mathrm{p}<0.001)$ as compared to Group II whereas the time spent in the center was not found to be statistically significant in all the groups.

\section{Morris water maze test}

The result of the Morris water maze test for escape latency is reported in Figs. 5 and 6. In the $3^{\text {rd }}$ day of training in Morris water maze test, in Group II treated with mercuric chloride, the escape latency was increased significantly as compared with the Group I, i.e., controls $(p<0.05)$. In the $4^{\text {th }}$ day and $5^{\text {th }}$ day, the escape latency was decreased significantly in Group I, Group III, Group IV, Group V, and Group VI as compared to Group II.

The result for path length in the Morris water maze test is reported in Fig. 7. In the $3^{\text {rd }}$ day of training in Morris water maze test, in Group II treated with mercuric chloride, the path length was increased

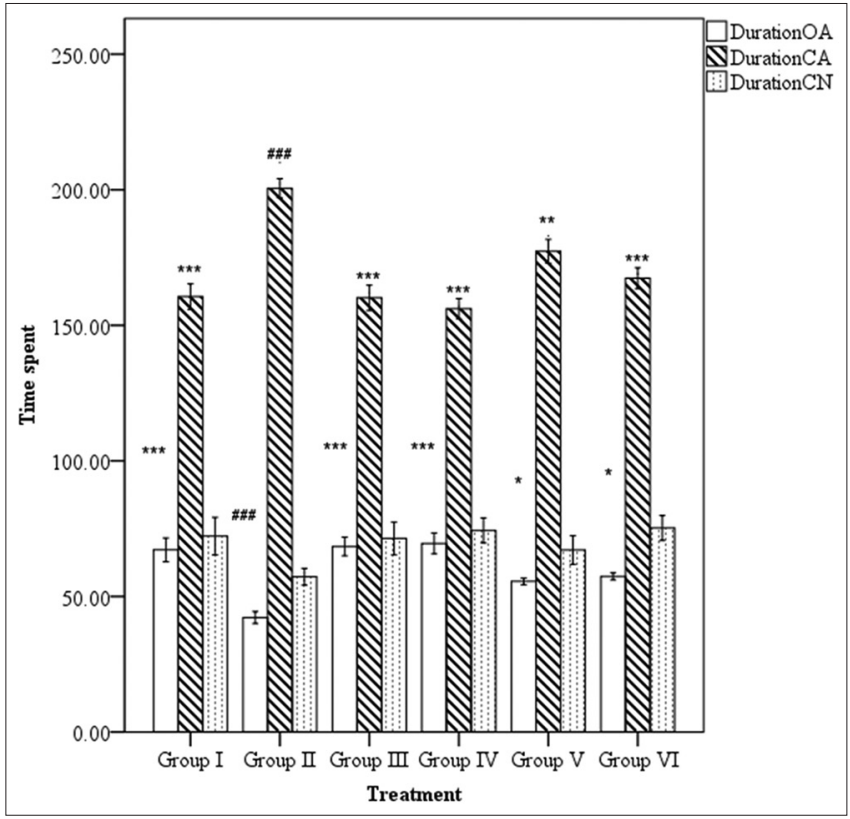

Fig. 3: Time spent in open (Duration $\mathrm{OA}$ ) and closed arms (Duration CA) and in the center (Duration CN) in elevated plus maze. Each column represents mean $\pm \operatorname{SEM}(n=6)$.

Comparisons were made using one-way analysis of variance followed by Turkey's Multiple Comparison test $(* \mathrm{p}<0.05$; ${ }^{* *} \mathrm{p}<0.01 ;{ }^{* * *} \mathrm{p}<0.001$ vs. Group II and ${ }^{\#} \mathbf{p}<0.05$; ${ }^{\# \#} \mathbf{p}<0.01$; $\# \#$ p $<0.001$ vs. Group I)

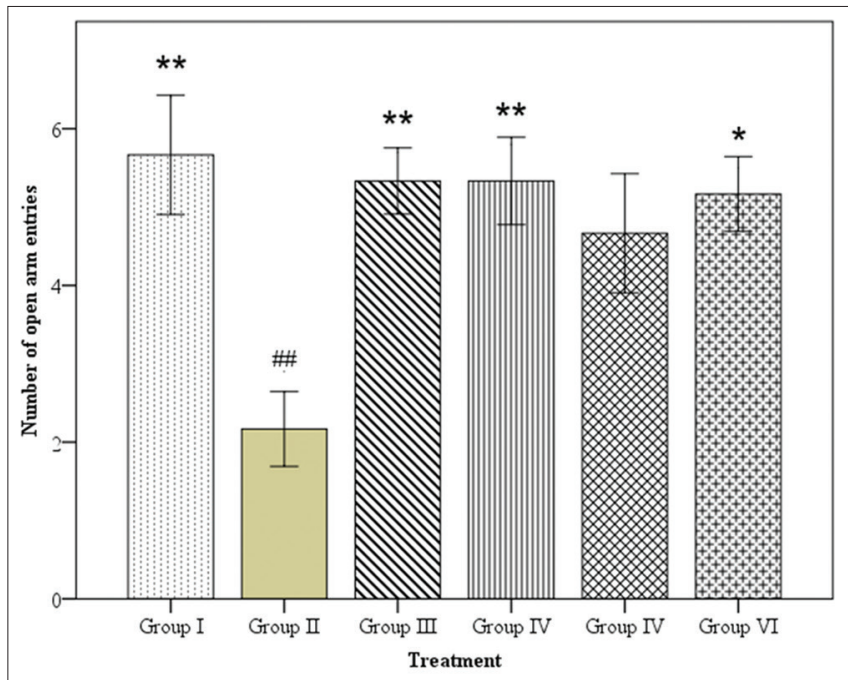

Fig. 4: Number of entries into open arms in elevated plus maze. Each column represents mean \pm SEM $(n=6)$. Comparisons were made using one-way analysis of variance followed by Turkey's multiple comparison test $\left({ }^{*} \mathrm{p}<0.05 ;{ }^{* *} \mathrm{p}<0.01 ;{ }^{* * *} \mathrm{p}<0.001 \mathrm{vs}\right.$. Group II and ${ }^{\#} p<0.05 ;{ }^{\# \#} \mathbf{p}<0.01 ;{ }^{\# \#} \mathbf{p}<0.001$ vs. Group I)

significantly as compared with the Group I, i.e., controls $(\mathrm{p}<0.05)$. In the $4^{\text {th }}$ day, the path length was decreased significantly in Group I ( $\left.p<0.01\right)$, Group III $(\mathrm{p}<0.001)$, Group IV $(\mathrm{p}<0.001)$ and Group VI $(\mathrm{p}<0.01)$ as compared to Group II. In the $5^{\text {th }}$ day, the path length was decreased significantly in Group I $(\mathrm{p}<0.001)$, Group III $(\mathrm{p}<0.001)$, Group IV $(p<0.001)$, Group V ( $<0.001)$, and Group VI $(p<0.001)$ as compared to Group II.

The number of annulus crossed is reported in Fig. 8. A significant decrease in the number of annulus crossed was observed in Group II 

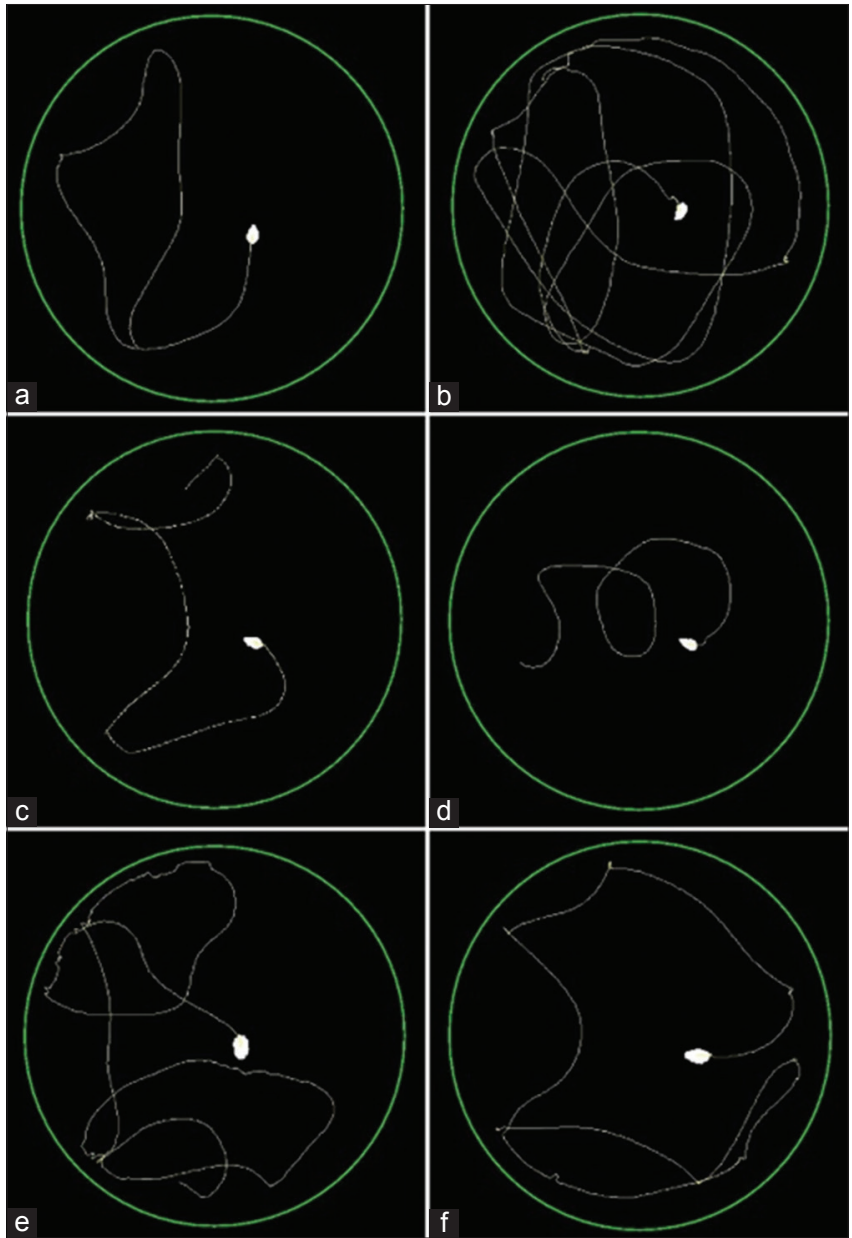

Fig. 5: Representative images of tracking of mice behavior in the Morris water maze test (a) Group I, (b) Group II, (c) Group III, (d) Group IV, (e) Group V, (f) Group VI

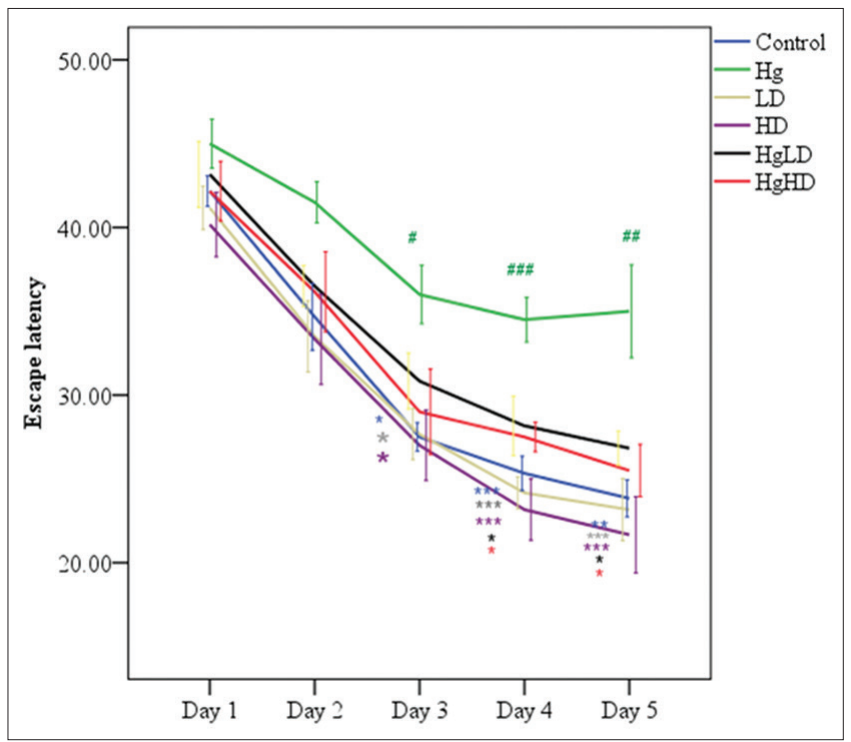

Fig. 6: Escape latency in Morris water maze. The data are represented as mean $\pm \operatorname{SEM}(n=6)$. Comparisons were made using one-way analysis of variance followed by Turkey's multiple comparison test $\left({ }^{*} \mathbf{p}<0.05 ; * * p<0.01 ; * * * p<0.001\right.$ vs. Group II and ${ }^{\#} \mathrm{p}<0.05$; \#\# $\mathrm{p}<0.01$; $\# \# \#$ p $<0.001$ vs. Group I; Group I=Control; Group II=Hg; Group III=LD; Group IV=HD; Group V=HgLD; Group VI=HgHD)

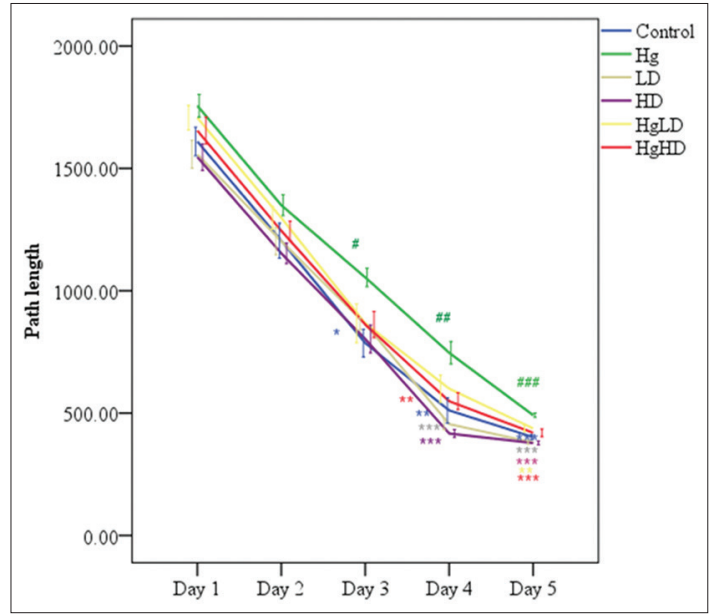

Fig. 7: Path length in Morris water maze. The data are represented as mean $\pm \operatorname{SEM}(n=6)$. Comparisons were made using one-way analysis of variance followed by Turkey's multiple comparison test $\left({ }^{*} \mathbf{p}<0.05 ;{ }^{* *} \mathbf{p}<0.01 ;{ }^{* * *} \mathrm{p}<0.001\right.$ vs. Group II and $\# \mathbf{p}<0.05 ; \# p<0.01 ; \# \# p<0.001$ vs. Group I; Group I=Control; Group II=Hg; Group III=LD; Group IV=HD; Group V=HgLD; Group VI=HgHD)

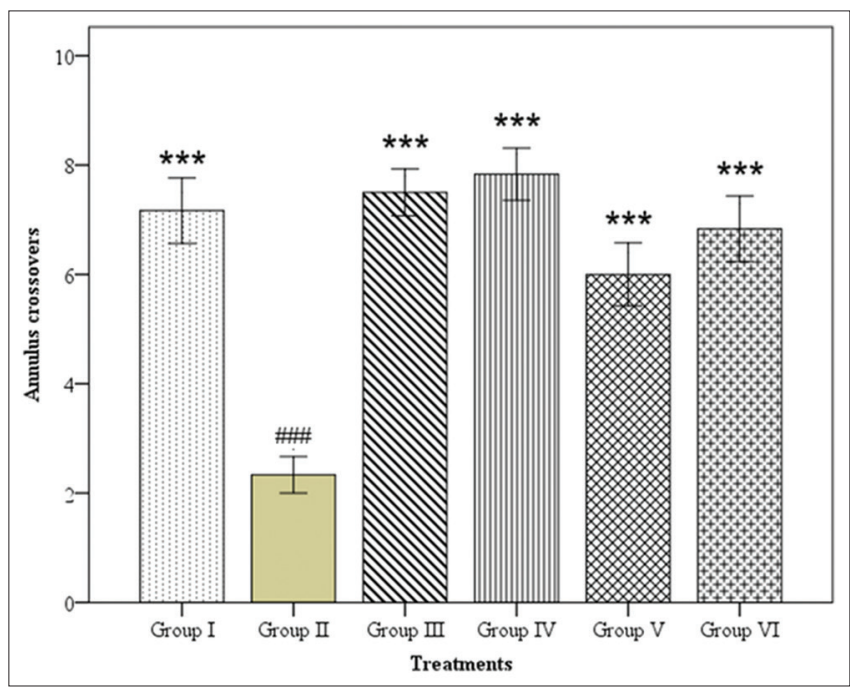

Fig. 8: Number of annulus crossed in Morris water maze. Each column represents mean $\pm \operatorname{SEM}(n=6)$. Comparisons were made using one-way analysis of variance followed by Turkey's multiple comparison test $\left(* \mathbf{p}<0.05 ;{ }^{* *} \mathbf{p}<0.01 ;{ }^{* * *} \mathbf{p}<0.001\right.$ vs. Group II and ${ }^{\#} \mathbf{p}<0.05 ; " \# p<0.01 ; " \# \#$ p $<0.001$ vs. Group I)

as compared with the Group I, i.e., controls $(\mathrm{p}<0.001)$. However, a significant increase in the annulus crossed was observed in Group I ( $p<0.001)$, Group III ( $\mathrm{p}<0.001)$, Group IV ( $\mathrm{p}<0.001)$, Group V $(\mathrm{p}<0.001)$, and Group VI $(\mathrm{p}<0.001)$ as compared to Group II.

\section{DISCUSSION}

Plant extracts have a wide range of medicinal actions, and throughout history, they have been used to treat many different types of diseases. More recently, scientists have begun investigating the biological activities of medicinal plants, including their neuroprotective actions [20]. One of the important steps in evaluating the action of a substance on the CNS is to observe its effects on the behavior of the animal. In the present study, the effect of aqueous extract of $\mathrm{HJ}$ on certain mercury-induced neurobehavioral alterations has been evaluated. 
Open field test is one of the most commonly used tests to measure behavior in animal models. It is a fast and relatively easy test that provides a variety of behavioral information ranging from the general ambulatory ability to data regarding the emotionality of the subject animal. A number of important conventional and ethological parameters can be collected and analyzed during the performance of the open field test [15]. In the present study, the open field test was used to evaluate locomotor activity in mice. The result of the test indicated that mercuric chloride significantly decreased locomotor activity as compared to the control group. The decrease in locomotion implies depression effect on CNS. It also gives an indication of the level of excitability of the CNS, and the decrease may be closely related to sedation resulting from the depression of the CNS. The group cotreated with mercuric chloride and plant extract showed a significant increase in locomotor activity as compared to mercuric chloride treated group.

The forced swimming test is one of the most widely used assays for the study of depressive-like behavior in rodents. The forced swimming test is used for evaluation of antidepressant drugs, antidepressant efficacy of new compounds, and experimental manipulations that are aimed at preventing depressive-like states [21]. When mice are forced to swim in an inescapable situation, after an initial period of vigorous activity, adopt a characteristic immobile posture in which they remain floating passively in the water making only those movements necessary to keep their heads above water [22]. The immobility reflects a state of lowered mood in which the animals have given up hope of finding an exit and have resigned themselves to the experimental situation. This immobility has been described as a symptom of behavioral despair and have been suggested as animal models of human depression. The significant increase in immobility time as compared to control group indicates depressant activity of mercuric chloride, which is opposite to the effect of the Groups V and VI which received both mercuric chloride and plant extract indicating antidepressant activity of the plant extract.

The elevated plus-maze test is now one of the most widely used models in neurobiological research on anxiety. It is based on the natural aversion of rodents to heights and open spaces. The introduction of mice to an elevated plus maze induces an exploratory cum fear drive which results in anxiety. Anxiolytic compounds by decreasing anxiety, increase the open arm exploration as well as the number of entries into the open arm [23]. In the present study, mercuric chloride treated group showed to decrease the time spent in open arms and also the number of entries in open arms. Whereas the group cotreated with mercuric chloride and plant extract showed to reverse the effects of mercuric chloride treated group. Thus, we can infer that the plant at the doses studied does possess anxiolytic activity.

The Morris water maze was first established by neuroscientist Richard G. Morris; it is one of the most widely used tasks in studies of spatial learning with rodents. This is a test for rodents that relies on distal cues to navigate from start locations around the perimeter of an open swimming arena to locate a submerged escape platform [24]. Spatial learning is assessed across repeated trials and reference memory is determined by a preference for the platform area when the platform is absent. As shown in Fig. 6, training of mice for 5 days in Morris water maze leads to progressive improvement of acquisition, the ability of mice to explore the hidden platform in the target quadrant. The decline in latency time indicates that mice got trained with the task given on the maze [19]. This is further evident by the decrease in path length (Fig. 7). Exposure to mercuric chloride resulted in a significant increase $(p<0.05)$ in the latency and path length as compared to the control group. The mice administered with plant extract and mercuric chloride, i.e., in Group V and VI showed a significant decrease in the latency and path length as compared to mercuric chloride treated group. In the probe trial test, in which the hidden platform was removed, mice exposed to mercuric chloride showed significant a decrease $(\mathrm{p}<0.05)$ in number of platform crossings (Fig. 8) as compared to the control group. Conversely, the Groups III, IV, V, and VI mice which were given the treatment of $\mathrm{HJ}$ showed a significant increase $(\mathrm{p}<0.05)$ in the number of platform crossings as compared to mercuric chloride groups. This indicates that the $\mathrm{HJ}$ possesses the ability to enhance spatial learning and memory.

\section{CONCLUSION}

The results obtained from the behavioral study suggest that mercuric chloride caused neurobehavioral changes which were ameliorated by the extract up to some degree. The behavioral study also revealed that the extract possesses neuroprotective potential with anti-depressant and anxiolytic activities and to improve learning and spatial memory in mice. However, more study is required to understand the mechanism of neuroprotective action of the plant extract against mercuric chloride induce neurotoxicity and the phytochemical components responsible for it.

\section{AUTHORS' CONTRIBUTIONS}

All the authors contributed equally.

\section{CONFLICTS OF INTEREST}

The authors declare that there are no conflicts of interest regarding the publication of this paper.

\section{REFERENCES}

1. Kabir I, Ansari I. A review on in vivo and in vitro experimental models to investigate the anti-inflammatory activity of herbal extracts. Asian J Pharm Clin Res 2018;11:29-35.

2. Kotteswari M, Rao MR, Prabhu K, Kumar S, Shil S. Antioxidant studies of one ayurvedic medicine aswagandharishtam. Asian J Pharm Clin Res 2018;11:227-31.

3. Kumar GP, Khanum F. Neuroprotective potential of phytochemicals. Pharmacogn Rev 2012;6:81-90.

4. Phukan P, Bawari M, Sengupta M. Promising neuroprotective plants from North-East India. Int J Pharm Pharm Sci 2015;7:28-39.

5. Ceccatelli S, Daré E, Moors M. Methylmercury-induced neurotoxicity and apoptosis. Chem Biol Interact 2010;188:301-8.

6. Chang LW. Neurotoxic effects of mercury a review. Environ Res 1977; 14:329-73.

7. Arya A, Sharma GD. Combined effects of cadmium and mercury on some biochemical and histochemical changes in liver, kidney and gills of Channa punctatus (Bloch). Int J Pharm Pharm Sci 2015;7:117-20.

8. Evans WC. Trease and Evans Pharmacognosy. $4^{\text {th }}$ ed. Singapore: Harcourt Brace and Company, Asia Pvt Ltd.; 1997.

9. Fisher DB. Protein staining of ribboned epon sections for light microscopy. Histochemie 1968;16:92-6.

10. Harborne JB. Phytochemical Methods. London: Chapman and Hall Ltd; 1973.

11. Kokate CK. Practical Pharmacognosy. $4^{\text {th }}$ ed. Madras: Vallabh Prakashan; 1999

12. Siddiqui AA, Ali M. Practical Pharmaceutical Chemistry. $1^{\text {st }}$ ed. New Delhi: CBS Publishers and Distributors; 1997.

13. Sofowora A. Medicinal Plants and Traditional Medicine in Africa. $2^{\text {nd }}$ ed. Nigeria: Spectrum Books; 1993.

14. Lorke D. A new approach to practical acute toxicity testing. Arch Toxicol 1983;54:275-87.

15. Pardon M, Pérez-Diaz F, Joubert C, Cohen-Salmon C. Age-dependent effects of a chronic ultramild stress procedure on open-field behaviour in B6D2F1 female mice. Physiol Behav 2000;70:7-13.

16. Porsolt RD, Le Pichon M, Jalfre M. Depression: A new animal model sensitive to antidepressant treatments. Nature 1977;266:730-2.

17. Lister RG. The use of a plus-maze to measure anxiety in the mouse. Psychopharmacology (Berl) 1987;92:180-5.

18. Gulyás M, Bencsik N, Pusztai S, Liliom H, Schlett K. AnimalTracker: An imageJ-based tracking API to create a customized behaviour analyser program. Neuroinformatics 2016;14:479-81.

19. Vorhees CV, Williams MT. Morris water maze: Procedures for assessing spatial and related forms of learning and memory. Nat Protoc 2006;1:848-58.

20. Iriti M, Vitalini S, Fico G, Faoro F. Neuroprotective herbs and foods from 
different traditional medicines and diets. Molecules 2010;15:3517-55.

21. Petit-Demouliere B, Chenu F, Bourin M. Forced swimming test in mice: A review of antidepressant activity. Psychopharmacology (Berl) 2005; $177: 245-55$

22. Porsolt RD, Bertin A, Blavet N, Deniel M, Jalfre M. Immobility induced by forced swimming in rats: Effects of agents which modify central catecholamine and serotonin activity. Eur J Pharmacol $1979 ; 57: 201-10$

23. Fernández Espejo E. Structure of the mouse behaviour on the elevated plus-maze test of anxiety. Behav Brain Res 1997;86:105-12.

24. Morris R. Developments of a water-maze procedure for studying spatial learning in the rat. J Neurosci Methods 1984;11:47-60. 